DOI: $\underline{10.20472 / E S .2016 .5 .4 .003 ~}$

\title{
TRUST, ECONOMIC GROWTH AND IMPORTANCE OF THE INSTITUTION
}

\section{HEEKYUNG SON}

\begin{abstract}
:
To keep making economic development continuously these days, there is a newly widespread awareness that it is definitely important to accumulate not only the physical and human capital but also the social capital. Many people have been paying attention to the trust which is one of the most representative factors in the social capital from an economic point of view as there are increasing empirical evidences to demonstrate pretty convincingly that the social capital significantly contributes to the economic growth.
\end{abstract}

In order to analyze how the social capital has an impact on the economic growth and what kind of factors make the level of trust changed, I adopted the Corruption Perception Index(CPI) as the indicator representing the "trust" so as to compare its CPI with those of other countries and analyzed data of the CPI from 34 OECD member countries from 2001 to 2013. As for the analysis of the variable factor for the level of trust, I made use of detailed institutional variables such as the political stability, the level of law and order, whether corruption is controlled or not, economic freedom and so on.

As a result, the CPI has a positive correlation with the growth rate of the real GDP per capita in the pooled OLS and random effect panel analysis while it has a negative correlation with them in the fixed effect panel analysis, which means there are a variety of regulations to control corruption and the more members of society put even more efforts to abide by social norms, the more negative the growth rate of the real GDP per capita gets as time goes by. I think that's why almost all of advanced countries already built such enough social norms and standards that they do not play any significant role in economy.

\section{Keywords:}

Social capital, GDP, Economic growth, Trust, Institution

JEL Classification: 043, C23

\section{Authors:}

HEEKYUNG SON, Statistical Research Institute in Statistics Korea, Korea, Republic of, Email: hkson08@korea.kr

\section{Citation:}

HEEKYUNG SON (2016). Trust, Economic Growth and Importance of the Institution. International Journal of Economic Sciences, Vol. V(4), pp. 32-50., 10.20472/ES.2016.5.4.003 


\section{Introduction}

Nowadays, the gap in Korean economy between the rich and the poor has been getting much bigger and bigger. On top of that, Korean economy has had difficulties in the sustainable growth due to the mounting calls for economic democratization. To keep making economic development continuously, there is a newly widespread awareness that it is definitely important to accumulate not only the physical and human capital but also the social capital. Many people have been paying attention to the trust which is one of the most representative factors in the social capital from an economic point of view as there are increasing empirical evidences to demonstrate pretty convincingly that the social capital significantly contributes to the economic growth.

The form of social capital to promote cooperation of members of society is broadly composed of the network, the norm and the trust. Among them, the trust is used the indicator measuring the social capital directly. In addition, a lot of researchers have started to conduct researches since the late of 1990 s as the trust is stressed as a factor affecting the economic growth concretely. Trust which represents the social capital consists of the private trust and the public trust. But I selected the public trust in this paper since it was definitely difficult to measure the private trust and analyzed the economic growth based on the public trust. First of all, I introduced social capital denoting the trust, especially the public trust as the economic variable and analyzed how the trust has an impact on the economic growth and what kind of factors make the level of trust changed after scrutinizing closely existing researches and checking out the role of trust as the social capital and the importance of trust for the economic development. As for the analysis of the variable factor for the level of trust, I made use of detailed institutional variables such as the political stability, the level of law and order, whether corruption is controlled or not, economic freedom and so on so that I could analyze them empirically and deduce implications from its findings.

\section{Existing researches}

According to findings from existing researches about the social capital, The fact is that social trust is one of the main factors which causes the economic growth since it exerts a significant effect on economic activities.

Arrow(1972) denoted that most of the economic backwardness around the world ultimately can be explained by the lack of mutual trust since almost all of business transactions contain the factor which means trust. It is sufficiently possible to insist that a lot of developing countries all over the world have a great difficulty in developing their economies due to the lack of mutual trust.

Putnam et al(1993) suggested that the social capital is even more important than physical 
and human capital for the economic growth as it can hasten economic activities through various channels.

Fukuyama(1995) pointed out that trust is the essential factor to determine the economic achievement and the level of trust that a society indigenously has in a country decides a country's welfare or competitiveness. Social capital has such characteristics of the public goods that people who do not participate in building the social capital directly can take advantage of it. Furthermore, social capital gets still bigger and bigger when the more members of society positively take part in setting up social capital, the more they exploit actively. After all, social capital has a positive externality as the more we use it, the bigger personal and social utility get. A country that accumulates social capital from this kind of characteristics of social capital can reduce costs for information and transactions so that it is able to boost its economy more and more. In other words, people living in the society that has high level of trust do not depend on legal regulations or contracts of employment but cut down on costs for companies through mutual trust among staff working together. And trust also has a positive effect on the economic growth indirectly by increasing the human capital and the real investment.

Knack and Keefer(1997) and Zak and Knack(2001) also described that there has a positive correlation between the economic growth rate or the level of income and the level of trust with the empirical analysis using data from the World Value Survey. They made use of Barro's investment and growth regression and analyzed 29 market countries so that they proved there is a correlation between trust and the economic growth. Especially, Knack and Keefer(1997) applied to the issue of Fukuyama(1995) for the empirical analysis and showed that the more a country that accumulates social capital, the higher economic growth rate is.

Zak and Knack(1998) extended the sample used in the model of Knack and Keefer(1997) and indicated that the low level of trust reduces the economic growth and investment.

Knack(2001) suggested that there is positive correlation which is statistically significant between social trust taking advantage of 2SLS with hierachical religion used as the Instrument Variable. Whiteley(2001) exploited the growth model of the neo-classical school and analyzed cross-sectional data from 34 countries from 1970 to 1992 with the growth rate of GDP per capita and found that there is the relation between trust and the economic growth. Depending on the result, all of the indicators of trust have a positive correlation and they affect as significantly as the human capital on the economic growth. 


\section{Analysis on the Trust and Economic Growth}

\section{1) Description of Data}

In a variety of research regarding the social capital, Data from the World Value Survey is used as the way to measure the trust. But there has been a lot of controversial issues related to the specific meaning of trust1 and its accuracy about trust dealt in this survey. Among them, Johnson and Mislin(2012) showed that the result of measuring the trust in the World Value Survey did not have any correlation with trustworthiness which means whether you can trust other people but had a strong correlation with the experimental trust which means whether you have an intention or a mind to trust other people. So in case of data from World Value Survey, there are some difficulties in utilizing Korea's data on a continuous basis and data from World Value Survey tend to mainly focus on the correlation between the social and economic characteristics of an individual. On the other hand, I just would like to narrow down the coverage of the trust and put an emphasis on the public trust and the relation between the social and economic characteristics of a country.

Therefore, I thought the Corruption Perception Index $(\mathrm{CPI})^{2}$ as a proxy of the trustworthiness which means that a nation's people can be trustworthy, which the priority is placed on the public trust. That's why I picked the Corruption Perception Index(CPI) up as the indicator representing the "trust" instead of using data from World Value Survey ${ }^{3}$ since I could let me compare its CPI with those of other countries and analyzed data of the CPI from $34^{4}$ OECD member countries from 2001 to 2013 so that I looked empirically into what kind of the correlation between the level of trust and the economic growth there is.

Examining variables used to estimate the rate of economic growth, I regarded the CPI as

\footnotetext{
1 The trust about other people is to score each criterion on a scale of certain levels, answering the question about each criterion on a scale of certain levels, answering the question about "Generally speaking, would you say that most people can be trusted or that you can't be too careful in dealing with people?"
}

2 Transparency International(https://www.transparency.org) has been compiling and announcing the indicator of trust in the public area that measures the level of corruption perception from 0 (highly corrupt) to 100 (Very clean) on a annual basis.

3 World Value Survey conducted by social scientists from leading universities worldwide is the most widely use d survey by a country and deals with changes about the social and political culture around the world. There ar e five waves until now; the wave from 1981 to 1984 dealt with 21 countries, the wave from 1989 to 1993 deal t with 43 countries, the wave from 1994 to 1998 dealt with 53 countries, the wave from 1999 to 2004 dealt wit h 70 countries, the wave from 2005 to 2008 dealt with 57 countries. and then Korea took part in this survey 0 n 1982, 1990, 1996, 2001 and 2005. In this survey, the level of the social trust is measured by a ratio of peo ple answering the question " Most people can be trusted"

4 Among 34 OECD member countries, data from 32 OECD member countries were used since there were some missing values in the two OECD member countries. 
the variable of trust in this paper so that I regress it on the growth rate of real GDP per capita that is the major independent determinant.

Barro(1999) pointed out several variables as the factor as followings to determine the growth rate of real GDP per capita. I adopted the explanatory variables by taking the natural log of the investment as a portion of the GDP. In addition, I measured the economic openness with the enrollment rate of the primary schools, the enrollment rate of the secondary schools and the sum of the export and import over the GDP getting all of the related data from the WDI database ${ }^{5}$

\section{< Table1> Basic Statistics}

\begin{tabular}{|c|c|c|c|c|c|c|}
\hline Variable & & Mean & Std. Dev. & Min & Max & Observations \\
\hline \multirow[t]{3}{*}{ gdp_rate } & overall & 1.23 & 2.99 & -14.57 & 11.07 & $\mathrm{~N}=416$ \\
\hline & between & & 1.06 & -0.45 & 4.40 & $n=32$ \\
\hline & within & & 2.80 & -17.74 & 7.89 & $T=13$ \\
\hline \multirow[t]{3}{*}{ cpi } & overall & 71.20 & 18.03 & 29.71 & 99.00 & $\mathrm{~N}=416$ \\
\hline & between & & 17.88 & 34.29 & 93.97 & $n=32$ \\
\hline & within & & 3.84 & 59.52 & 86.06 & $\mathrm{~T}=13$ \\
\hline \multirow[t]{3}{*}{ In_gdp } & overall & 0.43 & 0.86 & -3.35 & 2.40 & $\mathrm{~N}=416$ \\
\hline & between & & 0.44 & -0.24 & 1.55 & $n=32$ \\
\hline & within & & 0.75 & -2.86 & 1.93 & $\mathrm{~T}=13$ \\
\hline \multirow[t]{3}{*}{$g o v \_f$} & overall & 18.97 & 4.03 & 9.95 & 28.06 & $\mathrm{~N}=416$ \\
\hline & between & & 3.94 & 10.97 & 25.64 & $n=32$ \\
\hline & within & & 1.11 & 15.73 & 23.06 & $\mathrm{~T}=13$ \\
\hline \multirow[t]{3}{*}{ invest } & overall & 22.70 & 3.93 & 11.77 & 39.36 & $\mathrm{~N}=416$ \\
\hline & between & & 2.82 & 17.73 & 30.94 & $n=32$ \\
\hline & within & & 2.77 & 12.49 & 36.51 & $\mathrm{~T}=13$ \\
\hline \multirow[t]{3}{*}{ open } & overall & 89.55 & 54.69 & 20.26 & 371.44 & $\mathrm{~N}=416$ \\
\hline & between & & 54.29 & 26.65 & 313.60 & $n=32$ \\
\hline & within & & 11.38 & 32.52 & 147.39 & $T=13$ \\
\hline \multirow[t]{3}{*}{ edu1 } & overall & 89.67 & 33.74 & 0.00 & 121.58 & $\mathrm{~N}=416$ \\
\hline & between & & 9.81 & 60.49 & 99.17 & $n=32$ \\
\hline & within & & 32.33 & -9.50 & 129.23 & $T=13$ \\
\hline \multirow[t]{2}{*}{ edu2 } & overall & 92.51 & 36.56 & 0.00 & 159.15 & $\mathrm{~N}=416$ \\
\hline & between & & 15.54 & 54.98 & 128.02 & $n=32$ \\
\hline
\end{tabular}

5 http://databank.worldbank.org/data/home.aspx 


\begin{tabular}{|c|c|c|c|c|c|c|}
\hline & within & & 33.20 & -35.51 & 141.61 & $T=13$ \\
\hline \multirow[t]{3}{*}{ internet } & overall & 60.03 & 23.14 & 0.00 & 96.55 & $\mathrm{~N}=416$ \\
\hline & between & & 17.31 & 23.30 & 86.74 & $n=32$ \\
\hline & within & & 15.63 & 5.07 & 88.07 & $T=13$ \\
\hline \multirow[t]{3}{*}{ ecofree } & overall & 70.80 & 7.05 & 50.60 & 83.10 & $\mathrm{~N}=416$ \\
\hline & between & & 6.84 & 58.42 & 81.59 & $n=32$ \\
\hline & within & & 2.08 & 62.98 & 76.58 & $T=13$ \\
\hline
\end{tabular}

\section{2) Estimated Model}

I exploited the model of $\operatorname{Barro}(1991,1996)$ in order to analyze empirically how trust affects the economic growth and the equation is as follows.

$$
\nabla Y_{i, t}=\beta \log y_{i, 0}+\beta_{1} X_{i, t}+\beta_{2} Z_{i, t}+\varepsilon_{i, t}
$$

In this equation, $\nabla Y_{i, t}$ means the real growth rate of GDP per capita, $\log y_{i, 0}$ is the initial GDP per capita, $X_{i, t}$ is the growth factors used in the growth model of Solow which consist of the set of variables such as investment, government expenditure, human capital and so on but it is considered as the public trust. However, It contains that there might be possibility to have the endogeneity between the variables which are the real growth rate of GDP per capita and trust. Therefore, I scrutinized the Two Stage Least Square(2SLS) to control the endogeneity between the variables.

\section{3) Analysis Result}

$<$ Table 2> is the estimated result to analyze empirical data using the equation (1) of the Barro's economic growth. It shows that the estimated result of the Pooled OLS only used one independent variable, the $\mathrm{CPI}$ as the trust variable and those of panel data(Fixed Effect Estimator).

< Table 2> Estimated Result between the level of public trust and the growth rate of the GDP per capita

VARIABLES Pooled OLS RE FE

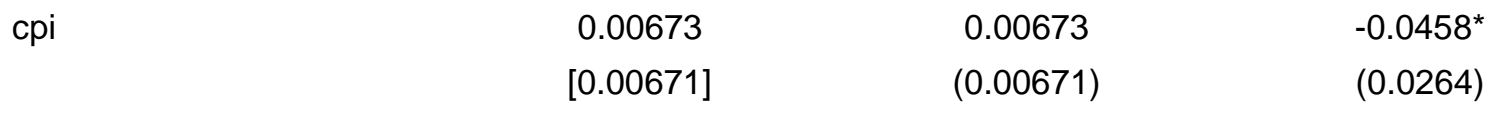




\begin{tabular}{lccc} 
In_gdp & $1.955^{* * *}$ & $1.955^{* * *}$ & $1.815^{* * *}$ \\
gov_f & {$[0.130]$} & $(0.130)$ & $(0.136)$ \\
& $-0.0664^{* *}$ & $-0.0664^{* *}$ & $-0.543^{* * *}$ \\
invest & {$[0.0289]$} & $(0.0289)$ & $(0.0964)$ \\
& $0.197^{* *}$ & $0.197^{* * *}$ & $0.341^{* * *}$ \\
edu1 & {$[0.0291]$} & $(0.0291)$ & $(0.0420)$ \\
& -0.00152 & -0.00152 & $-0.0210^{* *}$ \\
edu2 & {$[0.00816]$} & $(0.00816)$ & $(0.00943)$ \\
& 0.00267 & 0.00267 & $0.0212^{* *}$ \\
open & {$[0.00778]$} & $(0.00778)$ & $(0.00921)$ \\
& -0.000725 & -0.000725 & $0.0317^{* * *}$ \\
Constant & {$[0.00198]$} & $(0.00198)$ & $(0.00914)$ \\
& $-3.356^{* * *}$ & $-3.356^{* * *}$ & 3.354 \\
& {$[1.010]$} & $(1.010)$ & $(3.010)$ \\
Observations & & & 416 \\
R-squared & 416 & 416 & 0.544 \\
Number of idcode & 0.484 & 32 \\
\hline
\end{tabular}

Considering some of existing studies which depend on the OLS estimation using mean data from the long periods, It is a little bit new try to analyze data with the panel analysis.

In other words, Some estimated results were not consistent from the point of significance or directionality since they took an average of data from the duration of specific waves. So I decided to collect data by each factor on an annual basis and do the panel analysis instead of using OLS estimation so as to solve this problems and also estimated data by picking up the 2SLS with the instrument variable in order to avoid the possibility of the endogenous problem.

The Hausman Test suggests that it is suitable to choose the estimator of the Fixed and finds out that there is no reason to regard the variable of the level of trust as having endogeniety. Furthermore, shown as the table 2, the estimators of the level of public trust and the growth rate of GDP per capital are statistically significant at the level of 10\%.(Refer to the Appendix 1) Therefore, I adopted the Fixed Effect OLS and it said that all of the variables are statistically significant from 2001 to 2013 , especially it turns out that the government expenditure and investment as the portion of the GDP and the economic openness are statistically highly significant. In addition, $R^{2}$ which mean the fitness of the model was 0.54 and relatively significant compared to those of other models. By the way, the Fixed Effect Estimator shows the negative correlation between the level 
of public trust and the growth rate of the GDP per capita, while those of other OLS methods represented the positive correlation between them. This kind of phenomenon denoted that the results of the Fixed Effect Estimator was statistically significant since they reflect the characteristics of data but those of other OLS had a tendency to be overestimated. That is, what people have a high level of the corruption perception represents that the member of society set up a lot of institutional restrictions to avoid the corruption initiatively, which means that the OECD member countries are composed of advanced countries so that effects of future initiative institutions were reflected to the CPI. That's why the result of the fixed effect estimator indicates a negative correlation between the level of the public trust and the growth rate of the GDP per capita. From existing empirical results related to the trust, It is very significant to have a strong positive relationship between the level of the public trust and the growth rate of the GDP per capita since developing countries were mainly the subjects of the studies and lack of trust among people is rampant in their society. On the other hand, advanced countries like OECD member countries already have proper and appropriate regulations and institutions to control the corruption and establish the public trust, which is why the institution is significantly important for the economic growth and the public trust among people.

\section{Variable Factors of Public Trust}

Until now, I looked into the correlation between the public trust and the economic growth. So from now on, I would like to study what kind of factors can make the public trust to be changed. Berggren and Jordahl(2006) is one of the prominent thesises and it analyzed variable factors of the social trust by making use of ways of institutionalism. In this paper, they focused and analyzed the variables of economic freedom and its components. They admitted that it was not sufficient to do some analysis including economic variables and variables of the policy but there are some findings to analyze models including inequality of the income or the law and order in existing researches.

\section{1) Model and Data}

To set the model to analyze the level of social trust and figure out what kinds of factors makes it change, I set up the model as below adopting the institutional variable used in Knack and Keefer(1997) and Knack and Zalk(2002).

$$
\operatorname{Trust}_{i, t}=\alpha+\delta_{1} B_{i, t}+\psi_{2}+Z_{i, t}+\epsilon_{i, t}
$$


$Z_{i, t}$ is the institutional variables ${ }^{6}$ including the political stability(Political_Stability), the rule of law(Rule_law), the control of corruption(control_corruption) and the economic freedom(ecofree).

Trust $_{i, t}$ is the variable which presents the level of trust and it is used CPI already exploited to analyze what kind of the effect the public trust have on the economic achievement.

$B_{i, t}$ is the social economic condition which consist of the unemployment and provety and it means the indicator of an evaluation of pressure that might put a pressure on the government policy and cause social discontent. So $B_{i, t}$ describes that the bigger this indicator gets, the worse the social economic condition is. The social distance is internet density which means the number of using the internet per 100 people and it indicates that the social distance gets smaller as the number gets more. Lastly, $Z_{i, t}$ is a institutional variable and is regarded as the political stability, the rule of law, the control of corruption and the economic freedom.

\section{2) Analysis Result}

Quoting the empirical analysis method from the Knack and Zack(2002) in order to avoid the multi-collinearity among variables, I could analyze the macro-economic variable factors about the level of the social trust based on the variable of a social economic condition, the variable of a social distance and so on with a variety of institutional variables substituted stepwise,

\footnotetext{
6 http://knoema.com/
} 
$<$ Table 3> Result to analyze determinants of the level of the public trust

\begin{tabular}{|c|c|c|c|c|c|c|c|}
\hline VARIABLES & (1) & (2) & (3) & (4) & (5) & (6) & (7) \\
\hline \multirow[t]{2}{*}{ econ } & $-0.387^{* * *}$ & $-0.369^{* * *}$ & $-0.368^{* * *}$ & $-0.360^{\star \star *}$ & $-0.410^{\star * *}$ & $-0.375^{\star \star \star}$ & $-0.358^{* * *}$ \\
\hline & [0.0803] & -0.0795 & -0.0792 & -0.0807 & -0.0813 & -0.0824 & -0.082 \\
\hline \multirow[t]{2}{*}{ internet } & -0.0158 & $0.0301^{* *}$ & $0.0283^{\star *}$ & $0.0282^{\star *}$ & -0.0112 & 0.000414 & 0.00108 \\
\hline & [0.0132] & -0.0137 & -0.0137 & -0.0137 & -0.0146 & -0.0153 & -0.0152 \\
\hline \multirow[t]{2}{*}{ ecofree } & $0.396^{* * *}$ & $0.362^{* \star *}$ & $0.352^{* * *}$ & $0.358^{* * *}$ & $0.369^{* * *}$ & $0.339^{* * *}$ & $0.280^{\star * *}$ \\
\hline & {$[0.0977]$} & -0.0971 & -0.0969 & -0.0977 & -0.0967 & -0.0972 & -0.099 \\
\hline \multirow[t]{2}{*}{ control_corruption } & & $1.437^{\star \star \star}$ & $3.408^{* * *}$ & $3.271^{* * *}$ & $4.301^{* * *}$ & $5.686^{\star * \star}$ & $5.838^{* * *}$ \\
\hline & & -0.446 & -1.112 & -1.139 & -1.173 & -1.321 & -1.312 \\
\hline \multirow[t]{2}{*}{ Government_Effectiveness } & & & $-2.277^{\star}$ & $-2.408^{* *}$ & 0.262 & 1.516 & 2.172 \\
\hline & & & -1.177 & -1.201 & -1.458 & -1.556 & -1.564 \\
\hline \multirow[t]{2}{*}{ Political_Stability } & & & & 0.498 & 0.904 & $1.663^{*}$ & $2.109^{* *}$ \\
\hline & & & & -0.888 & -0.887 & -0.946 & -0.954 \\
\hline \multirow[t]{2}{*}{ Regulatory } & & & & & $-4.808^{* \star *}$ & $-3.360^{\star *}$ & -1.488 \\
\hline & & & & & -1.525 & -1.65 & -1.787 \\
\hline \multirow[t]{2}{*}{ Rule_law } & & & & & & $-4.902^{* *}$ & -3.278 \\
\hline & & & & & & -2.195 & -2.265 \\
\hline \multirow[t]{2}{*}{ Voice } & & & & & & & $-5.219^{\star \star *}$ \\
\hline & & & & & & & -1.996 \\
\hline \multirow[t]{2}{*}{ Constant } & $46.94^{* * *}$ & $48.27^{\star \star \star}$ & $49.29^{* * *}$ & $48.76^{\star \star \star}$ & $48.19^{\star \star \star}$ & $49.80^{\star \star \star}$ & $53.97^{* * *}$ \\
\hline & [6.802] & -6.733 & -6.729 & -6.8 & -6.724 & -6.727 & -6.863 \\
\hline Observations & 416 & 416 & 416 & 416 & 416 & 416 & 416 \\
\hline R-squared & 0.123 & 0.147 & 0.155 & 0.156 & 0.177 & 0.188 & 0.203 \\
\hline Number of idcode & 32 & 32 & 32 & 32 & 32 & 32 & 32 \\
\hline
\end{tabular}

Standard errors in brackets

${ }^{* * *} p<0.01,{ }^{* *} p<0.05,{ }^{*} p<0.1$ 
Checking out the level of the public trust for how the institutional variable influences, It is statistically significant that Improving the economic and social condition is increasing the public trust. As for the variable of the number of using the internet per 100 people is statistically significant in some of equations, equation (2), equation (3) and equation (4), which means that it got to improve partially the public trust to reduce the social distance.

The estimators of the economic freedom and the control of corruption are also statistically significant in all of the equations above, which shows that efforts to control corruption and the economic freedom play an important role in improving the trust. Furthermore, the Voice and Accountability, the Government Effectiveness, the Political Stability and Absence of Violence/Terrorism, the Regulatory Quality and the Rule of Law are statistically significant in some models as shown in the <Table 3>.

Therefore, It is imperative to accumulate the social capital called the trust in order to promote the economic trust. To do that, people should precede the effort to decrease a corruption in a country and the trust, especially public trust should be strictly protected under the legal institution and entailed in making allowance for economic freedom.

\section{Conclusion}

As discussed above, I empirically analyze the correlation between the public trust and the economic growth and variable factors of the public trust. The CPI has a positive correlation with the growth rate of the real GDP per capita in the pooled OLS and random effect panel analysis while it has a negative correlation with them in the fixed effect panel analysis, which means the panel analysis, especially fixed effect panel analysis is more suitable for this study according to Housman test than the pooled OLS calculating data on average.

The reason why the result shows that there is a negative correlation with the growth rate of the real GDP per capita in the fixed effect panel analysis is that my subjects of this study were OECD member countries involved in advanced countries. There are a variety of regulations to control corruption and it is natural that the more members of society put even more efforts to abide by social norms, the more negative the growth rate of the real GDP per capita gets as time goes by. I think that's why almost all of advanced countries already built such enough social norms and standards that they could not play any significant role in the economy anymore and sometimes it could be one of obstacles in the sustainable economic growth to have too many rules and regulations in our society.

From this empirical analysis, I could check out that there are various factors such as the control of corruption, the law and order, the government effectiveness and so on and basically, this kind of institutional compositions play really important roles in increasing 
the trust in our society and those things ultimately can end up building the social capital for a country. Advanced countries like OECD member countries already have proper and appropriate institutions to control the corruption and establish the public trust, which is why the institution is significantly important for the economic growth and the public trust among people but the public trust could have a negative effect on the economic growth once it attains a certain standard. For further information, next time I do a following study, I should consider and compare them with those of developing countries. In addition, It is imperative to accumulate the social capital called the trust in order to promote the economic trust. To do that, people should precede the effort to decrease a corruption in a country and the trust, especially public trust should be strictly protected under the legal institution and entailed in making allowance for economic freedom.

To sum up, It is no doubt that there is a significant correlation between trust and the economic growth and it is definitely important to accumulate the social capital, trust and to reduce corruption.

However, this study leaves much to be desired because I only focused on the public trust due to the time limited and difficulty of getting appropriate data in spite of being heavy on the private trust when it comes to the trust. In addition, It will be a lot more desirable to have much more distinctive and specific definition on the trust through an economic modeling since there are no unified definitions about what the social capital means in our society and a variety of differences among researchers. 


\section{Appendix. Panel Analysis between the public trust and the economic growth}

- Pooled OLS estimator

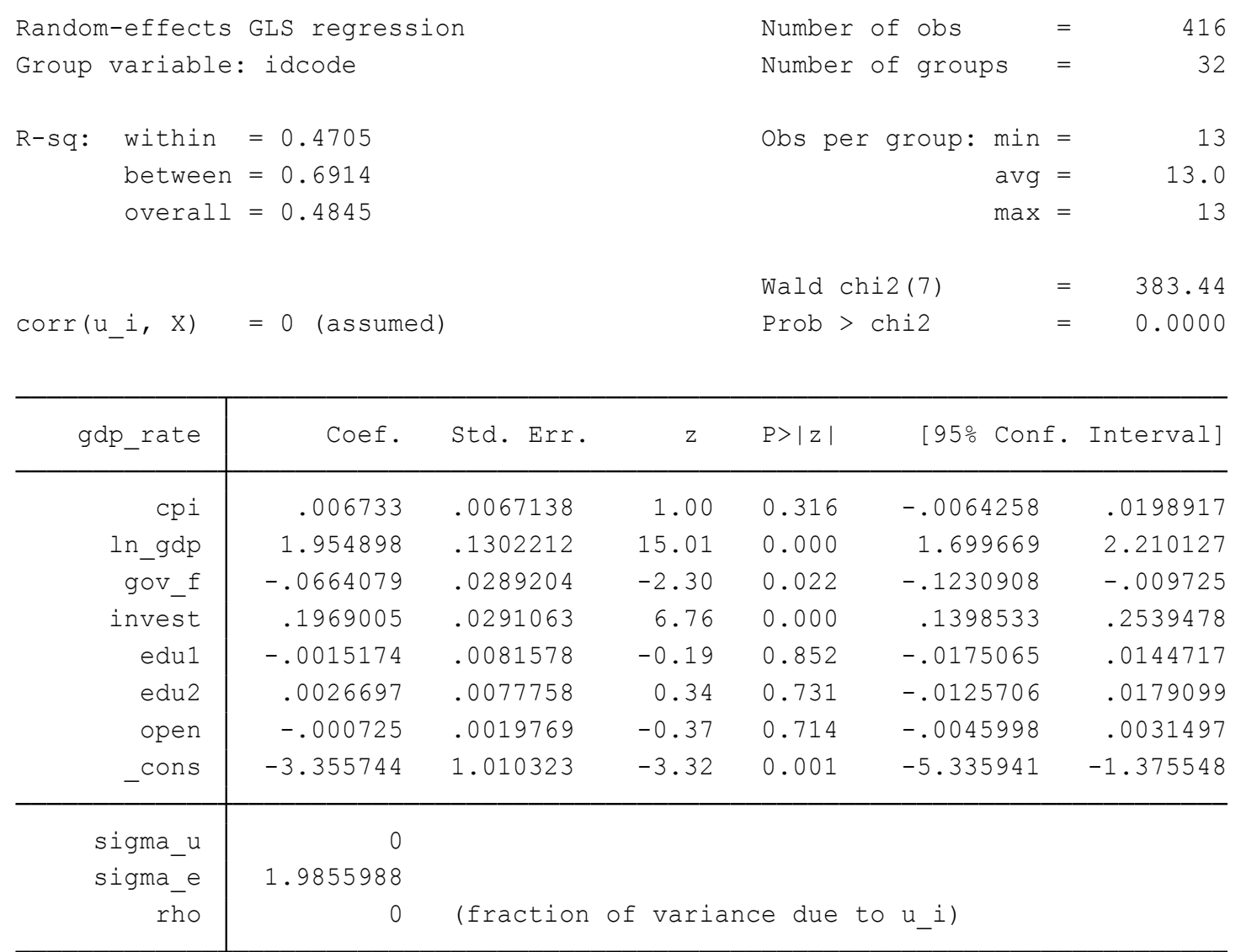


- Between estimator

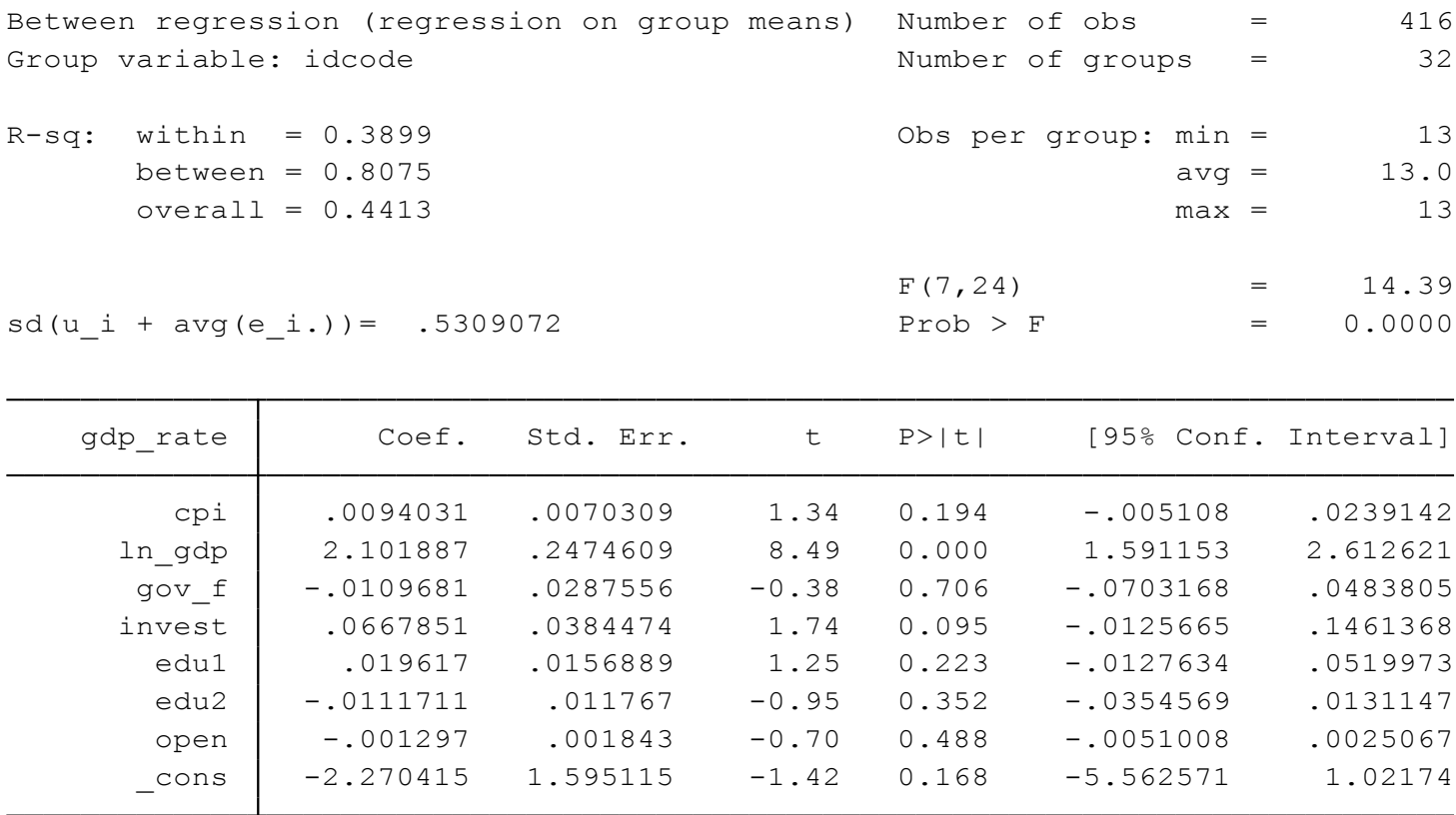

\section{- Fixed estimator}

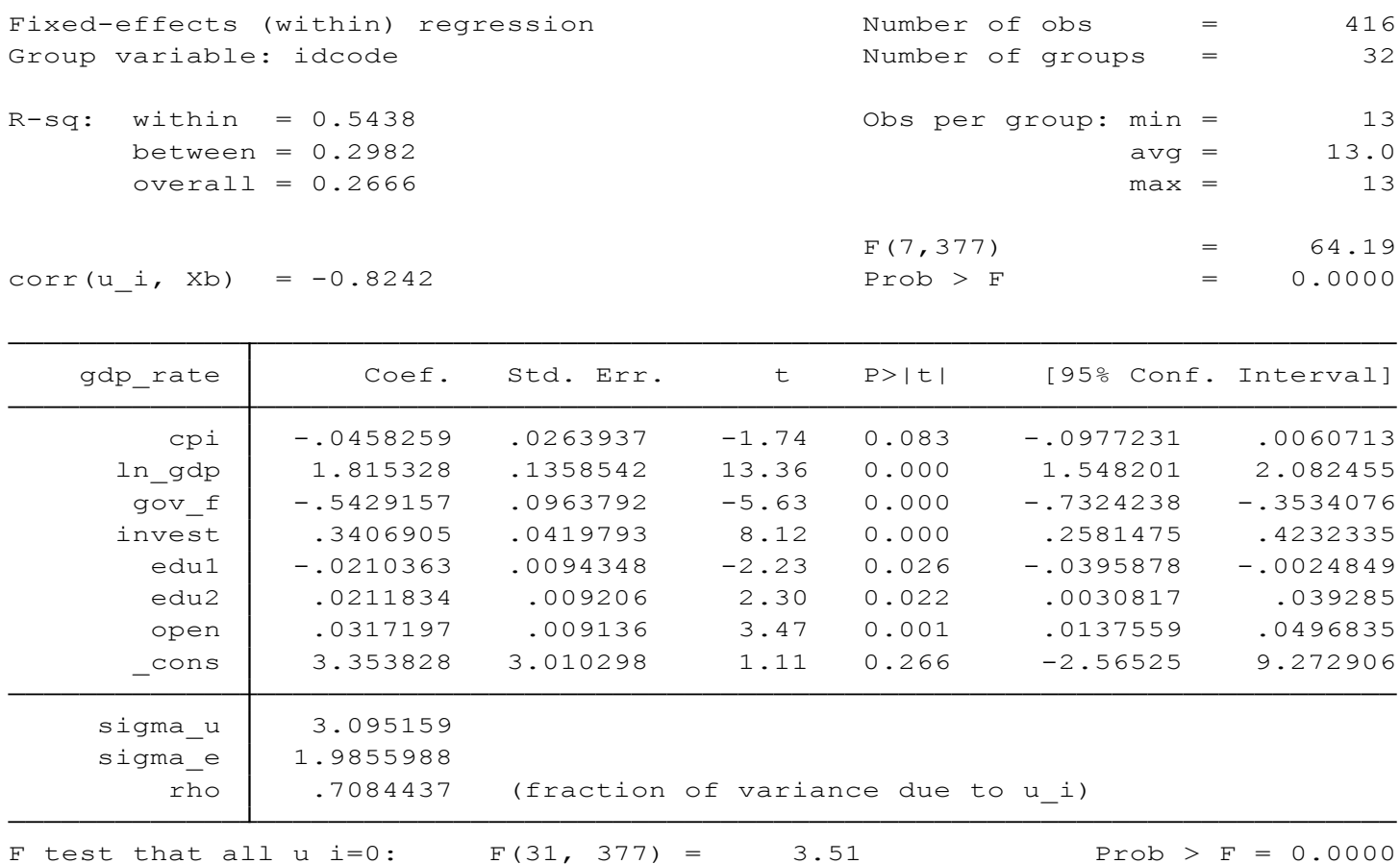


- Random effect estimator \& MLE

Random-effects GLS regression

Group variable: idcode

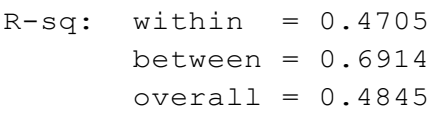

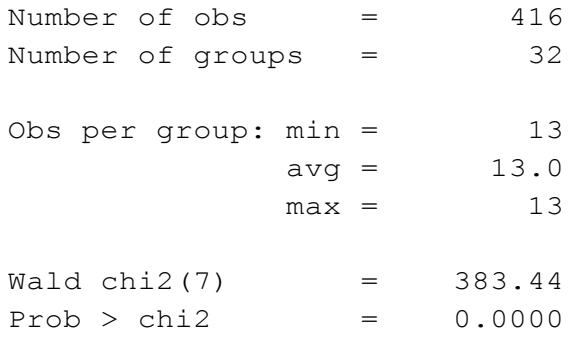

\begin{tabular}{|c|c|c|c|c|c|c|c|c|}
\hline gdp_rate & Coef. & Std. Err. & & z & $P>|z|$ & & [95\% Conf. & Interval] \\
\hline $\mathrm{cpi}$ & .006733 & .0067138 & & 1.00 & 0.316 & \multicolumn{2}{|r|}{-.0064258} & .0198917 \\
\hline In_gdp & 1.954898 & .1302212 & & 15.01 & 0.000 & \multicolumn{2}{|r|}{1.699669} & 2.210127 \\
\hline gov_f & -.0664079 & .0289204 & & $-2 \cdot 30$ & 0.022 & \multicolumn{2}{|r|}{-.1230908} & -.009725 \\
\hline invest & .1969005 & .0291063 & & 6.76 & 0.000 & \multicolumn{2}{|r|}{.1398533} & .2539478 \\
\hline edu1 & -.0015174 & .0081578 & & -0.19 & 0.852 & & -.0175065 & .0144717 \\
\hline edu2 & .0026697 & .0077758 & & 0.34 & 0.731 & & -.0125706 & .0179099 \\
\hline open & -.000725 & .0019769 & & -0.37 & 0.714 & & -.0045998 & .0031497 \\
\hline _cons & -3.355744 & 1.010323 & & $-3 \cdot 32$ & 0.001 & & -5.335941 & -1.375548 \\
\hline sigma_u & 0 & & & & & & & \\
\hline sigma_e & 1.9855988 & & & & & & & \\
\hline rho & 0 & (fraction & of & varia & ze due & to & $u_{-}$i) & \\
\hline
\end{tabular}

Random-effects ML regression

Group variable: idcode

Random effects u i Gaussian
Number of obs $=416$

Number of groups $=32$

Obs per group: $\min =13$

$\operatorname{avg}=13.0$

$\max =13$

$\mathrm{LR} \operatorname{chi2}(7)=275.72$

Prob $>$ chi2 $=0.0000$

\begin{tabular}{|c|c|c|c|c|c|c|}
\hline gdp_rate & Coef. & std. Err. & z & $P>|z|$ & Conf. & Interval] \\
\hline $\mathrm{cpi}$ & .0054741 & .0083566 & 0.66 & 0.512 & -.0109045 & .0218528 \\
\hline In_gdp & 1.922613 & .1348561 & 14.26 & 0.000 & 1.6583 & 2.186926 \\
\hline gov_f & -.0956926 & .0454319 & -2.11 & 0.035 & -.1847375 & -.0066477 \\
\hline invest & .2365423 & .0444218 & 5.32 & 0.000 & .1494771 & .3236075 \\
\hline edul & -.007222 & .009659 & -0.75 & 0.455 & -.0261534 & .0117094 \\
\hline edu2 & .0075453 & .0090908 & 0.83 & 0.407 & -.0102723 & .0253629 \\
\hline open & .0000577 & .0026474 & 0.02 & 0.983 & -.0051312 & .0052465 \\
\hline _cons & -3.606253 & 1.162055 & -3.10 & 0.002 & -5.883839 & -1.328667 \\
\hline /sigma_u & .5114186 & .2641454 & & & .1858381 & 1.407402 \\
\hline /sigma_e & 2.094642 & .0817351 & & & 1.940417 & 2.261125 \\
\hline rho & .0562583 & .0566229 & & & .0051296 & .2719254 \\
\hline
\end{tabular}

Likelihood-ratio test of sigma_u=0: $\operatorname{chibar2}(01)=1.63$ Prob>=chibar2 = 0.101 


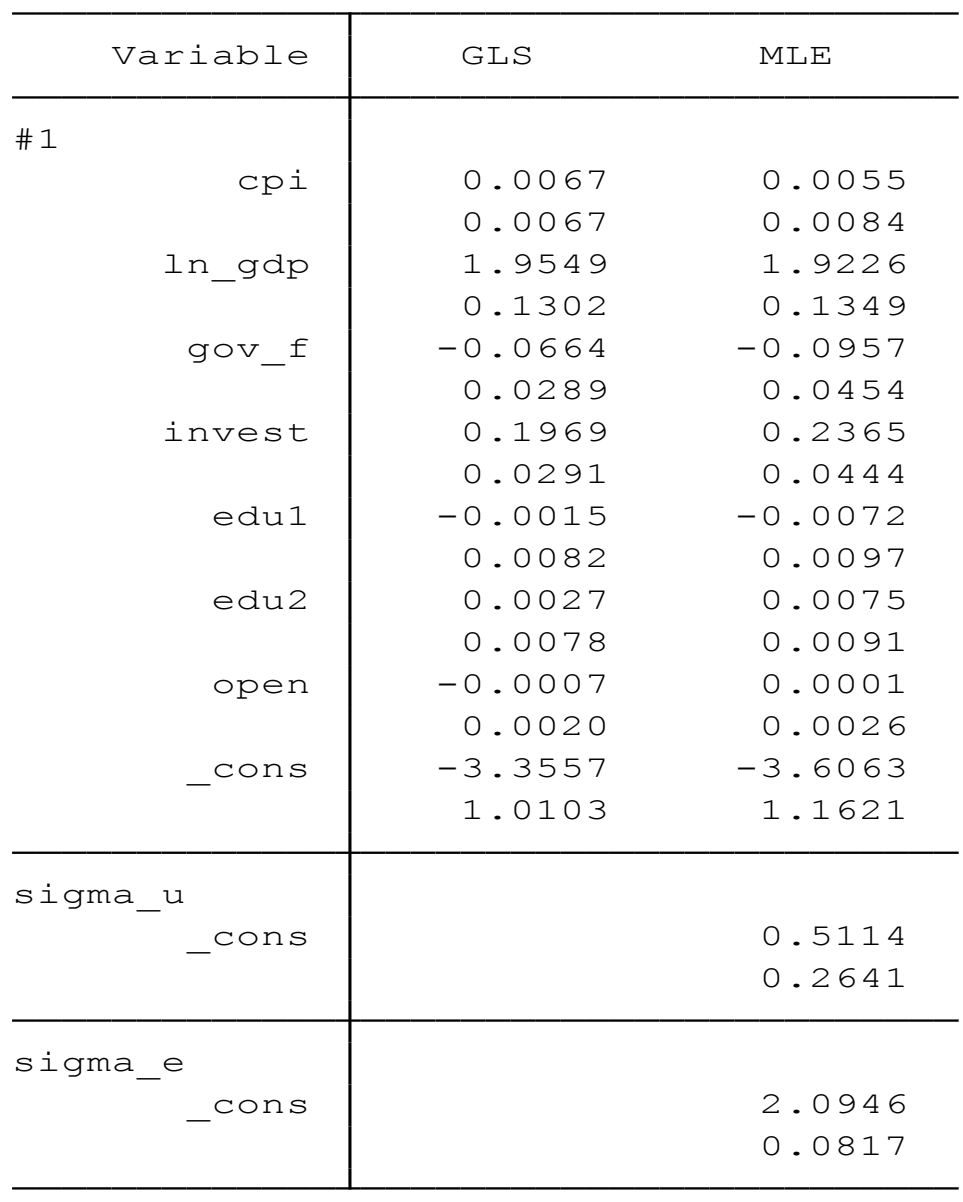

legend: b/se

\section{- Between/Fixed/Random effect estimator}

\begin{tabular}{|c|c|c|c|}
\hline Variable & be_model & fe_model & re_model \\
\hline cpi & .0094 & -.0521 & .00673 \\
\hline In_gdp & $2.1 * \star \star$ & & $1.95 * \star \star$ \\
\hline gov_f & -.011 & 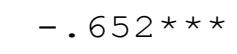 & $-.0664 * \star$ \\
\hline invest & $.0668 *$ & $.449 \star \star \star$ & $.197 \star \star \star$ \\
\hline edu1 & .0196 & -.0116 & -.00152 \\
\hline edu2 & -.0112 & .014 & .00267 \\
\hline open & -.0013 & $.0305 * \star \star$ & -.00073 \\
\hline _cons & -2.27 & 4.13 & 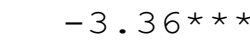 \\
\hline
\end{tabular}




\section{- Hausman Test}

- hausman fe re, sigmamore

\begin{tabular}{|c|c|c|c|c|}
\hline & \multicolumn{2}{|c|}{ - Coefficients - } & \multirow{3}{*}{$\begin{array}{c}(b-B) \\
\text { Difference }\end{array}$} & \multirow{3}{*}{ 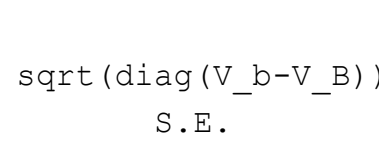 } \\
\hline & (b) & (B) & & \\
\hline & fe & $r e$ & & \\
\hline cpi & -.0458259 & .006733 & -.0525588 & .0280051 \\
\hline $\ln \_g d p$ & 1.815328 & 1.954898 & -.1395703 & .0708201 \\
\hline gov_f & -.5429157 & -.0664079 & -.4765078 & .1011062 \\
\hline invest & .3406905 & .1969005 & .14379 & .0353676 \\
\hline edu1 & -.0210363 & -.0015174 & -.0195189 & .006279 \\
\hline edu2 & .0211834 & .0026697 & .0185137 & .006359 \\
\hline open & .0317197 & -.000725 & .0324447 & .0097704 \\
\hline
\end{tabular}

$\mathrm{b}=$ consistent under $\mathrm{Ho}$ and $\mathrm{Ha}$; obtained from xtreg $\mathrm{B}=$ inconsistent under $\mathrm{Ha}$, efficient under Ho; obtained from xtreg

Test: Ho: difference in coefficients not systematic

$$
\begin{array}{rlrl}
\operatorname{chi2}(7) & = & (b-B)^{\prime}\left[\left(V_{-} b-V_{-} B\right)^{\wedge}(-1)\right](b-B) \\
& = & & 72.60 \\
\text { Prob }>\operatorname{chi} 2 & = & & 0.0000
\end{array}
$$

$=>$ Null hypothesis was rejected at the level of $1 \%$ significance since the $p$ value is smaller than 0.01 . Therefore, it is proper to choose not the random effect model but the fixed effect model as the estimator of the random effect model is not a consistent estimator 


\section{References}

Arrow, K., "Gift and Exchanges", Philosophy and Public Affairs, 1(4) , 1972, 343-362.

Fukuyama, F., Trust : The Social Virtues and the Creation of Prosperity, The Free Press, 1995.

Knack, S., "Social capital and the quality of government: Evidence from the States", American Journal of Political Science, 2002, 772-785.

Knack, S. and P. Zak, "Building Trust: Public Policy, Interpersonal Trust, and Economic Development", Supreme Court Economic Review, 10, 2002, 91-107.

Knack, Stephen and Philip Keefer, "Does Social Capital Have an Economic Payoff? A Cross-Country Investigation", Quarterly Journal of Economics, 112(4) , 1997, 1251-1288.

Knack, Stephen, 2002. "Social capital, growth and poverty: a survey of cross-country evidence," MPRA Paper 24893

Nicolas Berggren and Henrik Jordah "Free to Trust: Economic Freedom and Social Capital". 2006.

Putnam, R. D., Making Democracy Work: Civic Traditions in Modern Italy, Princeton University Press, 1993.

Roth, F. M., "Social capital, trust, and economic growth: a cross-sectional and panel analysis", Dissertation, University Gottingen, 2007.

Zak, Paul J., and Stephen Knack,“Trust and Growth,” Economic Journal, 111(April) , 2001, 295-321. 